\title{
SMA in mitigation of extreme loads in civil engineering: Damping actions in stayed cables
}

\author{
Vicenç Torra ${ }^{1, a}$, Antonio Isalgue ${ }^{1}$, Carlota Auguet ${ }^{1}$, \\ Guillem Carreras $^{1}$, Francisco C. Lovey ${ }^{2, b}$, Patrick Terriault ${ }^{3, c}$, \\ Lamine Dieng ${ }^{4, d}$ \\ ${ }^{1}$ CIRG-Applied Physics, ETSECCPB, Polytechnical University of Catalonia, Barcelona, Catalonia, \\ E-08034 Spain \\ ${ }^{2}$ Centro Atomico Bariloche (CAB-IB) Bariloche, 8400 Argentina \\ ${ }^{3}$ LAMSI, ETS, Université de Québec, H3C 1K3 Montréal, Ca. \\ ${ }^{4}$ IFSTTAR - Centre de Nantes - Route de Bouaye - BP: 4129, 44341 Bouguenais, France

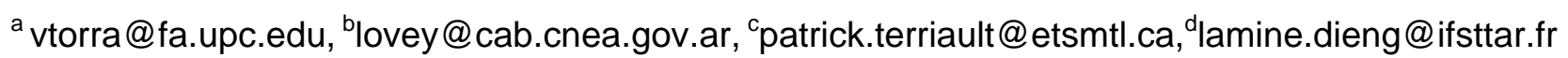

Keywords: Shape Memory Alloys, damping, passive systems, stayed cables damping, fatigue-life, Ansys simulation.

\begin{abstract}
Guaranteeing the use of Shape Memory Alloys (SMA) in mitigation of extreme load effects requires a deep study of the SMA behavior according to the specific requirements of the application. In particular, for a storm is necessary more than one million of working cycles. It is applied to two realistic cables in ELSA (JRC-Ispra, Italy) and in IFSTTAR (old LCPC in Nantes, France). The measurements establish that the SMA reduces drastically the oscillation amplitude. Technical suggestions for the preparation of the dampers are included. For instance, about the two available parameters in the SMA dampers: length $(\ell)$ and number $(N)$ of SMA wires. Moreover, a suitable simulation by proprietary SMA routine inside ANSYS is included.
\end{abstract}

\section{Introduction}

The strong winds or the rain and traffic and other external perturbations can induce oscillations in stayed cables of bridges. The millions of oscillation cycles with larger amplitudes induce progressive damage in the cables, in particular, in their fixation devices. The particular characteristics of NiTi SMA [1] suggest that it is a good candidate for its application in damping of the stayed cables. For the guaranteed application of the SMA as damping devices fo bridges, several conditions need to be studied and fulfilled. 1) Several millions of working cycles without fracture. 2) Appropriate resistance to outdoor conditions (wetting, temperature) in the expected lifetime. 3) Damper length invariant in their working conditions. 4) Well-known behavior of the hysteresis cycle and their parasitic effects related to cycling frequency, self-heating and associated heat transfer to surrounding air.

The SMA dampers were applied to two realistic cables, first (2009) at ELSA-JRC-EU (Ispra, Italy) to cable No. 1. The length was $45 \mathrm{~m}$ and the steel was situated inside a plastic protection refilled with wax that produces some intrinsic and relevant damping. The measurements established that the SMA duplicates de damping. Later, the behavior of the multilayer cable of DSOA-LCPC (2009 and 2010) was analyzed. With a length of $50 \mathrm{~m}$, the DSOA cable does not include any significant damping action. Impulse signals as the Heaviside return were used to induce the vibrations in the cable. The experimental study without and with damper establishes a spectacular reduction of the oscillations. The study includes ideas for the appropriate outline of the dampers and suitable simulation by proprietary SMA routine inside ANSYS.

The requirements for the use of SMA to damping of stayed cables are similar to the requirements for earthquakes, but the number of cable oscillations is extremely higher. For strong storms of 3 days the oscillation frequency is highly relevant. In the Iroise bridge for the Elorn River near Brest 
[2] $(1$ and $3 \mathrm{~Hz})$ or in St Nazaire bridge for the Loire River near Nantes [3] (18 Hz) the number of working cycles is close to 0.78 or to 4.67 millions. For the Echinghen Viaduct, the frequency is close to $5 \mathrm{~Hz}$ and the required cycles overcome 1.5 million.

When SMA will be used in mitigation of the oscillations in stayed cables for bridges (SCB), the good behavior for its appropriate requirements has to be guaranteed. For this, it is necessary to take into account the next conditions [4]:

A $_{\mathrm{SCB}}$ : larger fatigue life overcoming several millions of working cycles

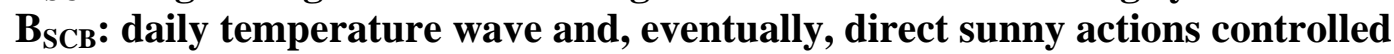

$\mathrm{C}_{\mathrm{SCB}}$ : the damper length need to remain invariant

$D_{\mathrm{SCB}}$ : no relevant changes in wind pauses, i.e., local changes of weather.

$E_{\mathrm{SCB}}$ : aging effects avoided in series of sunny days (temperature effects determined).

$F_{\text {SCB }}$ : self-heating not relevant or well determined.

$\mathrm{G}_{\mathrm{SCB}}$ : dampers with recoverable behavior were required.

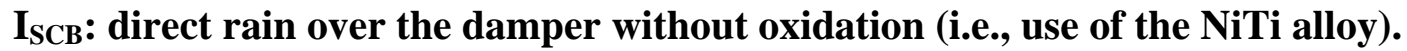

$\mathbf{J}_{\mathrm{SCB}}$ : wellknown effects of aging of stressed material.

The main interest focuses in the necessary tools for accurate simulation of the damper behavior in their application. It is essential a well determined knowledge of the dissipated energy and of the hysteresis cycle shape for a correct simulation.

In the experiments realized for this paper, the NiTi wires have been furnished in pseudo-elastic state by Special Metals, USA (actually SAES Getters, Italy). The wires of $2.46 \mathrm{~mm}$ of diameter have been trained by 20 or 100 cycles with a maximal deformation of $8 \%$ before using as a damper.

\section{Application of the NiTi dampers in stayed cables}

In general the dampers are structured with disks or plates permitting the use of the N SMA wires (for $\mathrm{N}>2$ in a hamster box) with appropriate length and slip mechanisms avoiding compression and shortened for fine tune of pre-stress as described in Fig. 1. Two sets of experimental measurements are realized in realistic cables. The cable No 1 was used in the ELSA-JRC-EU [5, 6], with $45 \mathrm{~m}$ of length is wrought with four sets of steel wires of $15 \mathrm{~mm}$ of diameter, and the IFSTTAR cable with $50 \mathrm{~m}$ of length.

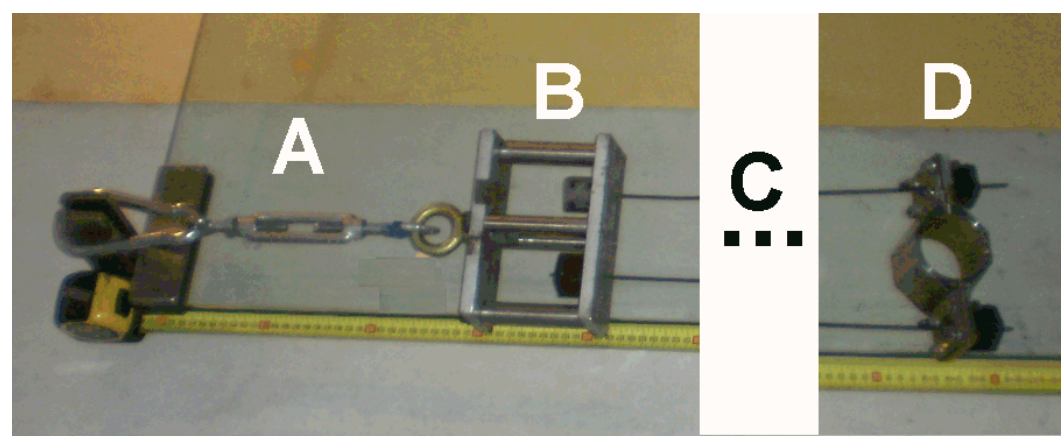

Figure 1. Damper for cables with 2 wires of NiTi: A: shortened, B: wires fixation, C: length of the SMA wires, D: fixation for IFSTTAR cable.

\section{Cable No 1 of ELSA}

For a practical control of the SMA in damping for stayed cables several measurements were carried out in the cable no 1 of the ELSA - JRC - EU laboratory facility. The cable no. 1 with 4 sets of steel wires is filled with wax that produces an intrinsic and relevant "self damping". Only one wire of NiTi SMA was used $(2.46 \mathrm{~mm}$ of diameter and, after 100 cycles of training, $4.14 \mathrm{~m}$ of length). The analysis is devoted to determine the oscillations induced by external periodical forces (roughly 49, 98 and $196 \mathrm{~N}$ ) at the resonance frequency $1.8 \mathrm{~Hz}$ (free) and $2.05 \mathrm{~Hz}$ (SMA). When the SMA is included, several values of pre-stress are tested. The maximal cable oscillations, for 
instance $\pm 80 \mathrm{~mm}$, are equivalent to deformations below $3.9 \%$ in the SMA wire system. When the oscillations produce a deformation below $0.5 \%$ in the SMA system the martensitic transformation is not induced and no dissipation of energy by SMA takes place. Only the intrinsic effect of wax reduces the oscillation amplitude. The analysis is performed without and with the SMA as shows Fig. 2.

The action of SMA reduces the maximal amplitude to $1 / 3$ and increases the cable frequency from 1.8 to $2.05 \mathrm{~Hz}$. The SMA induces one force associate to the oscillation amplitude on the cable situated under $1500 \mathrm{~N}$. The cable 1 is filled with wax that produces an intrinsic and relevant "self damping”.
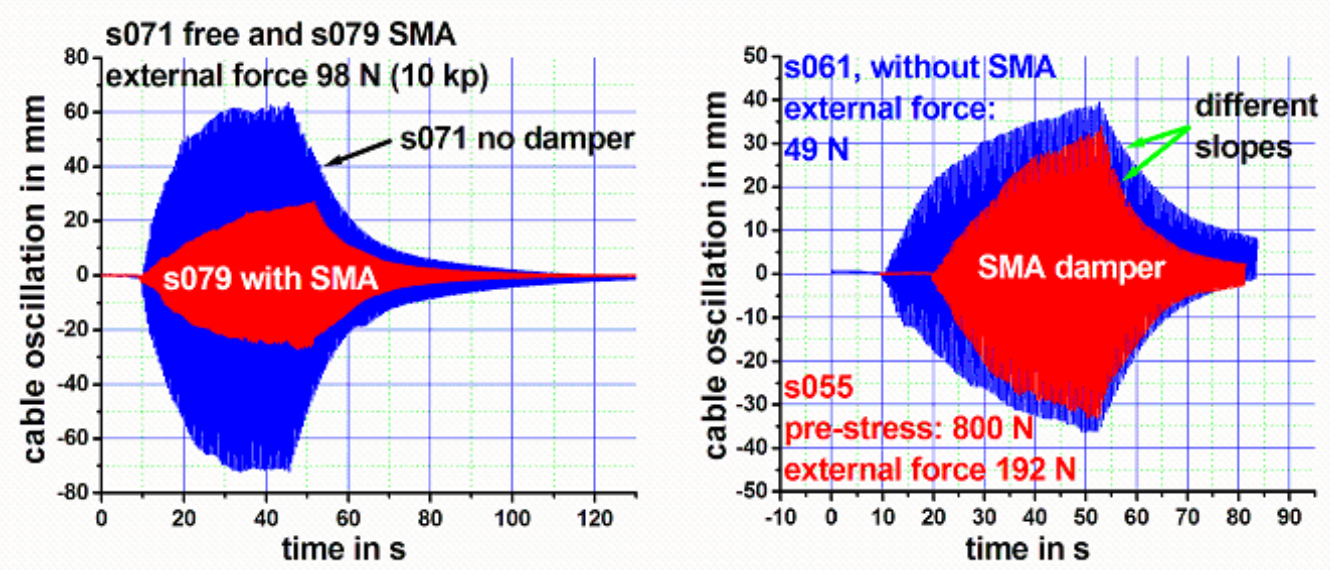

Figure 2. The cable displacements. Left: equal excitation without and with SMA damper. Right: Similar oscillations for loads of 49 and 192 N. The results show an increased slope with SMA.

The experimental results show the relevant and clear effects of the SMA damper. In particular Fig. 2 right shows the increased slope (two times) in comparison with spontaneous decay induced by the wax, when the cable is free (without SMA damper) (see, for some simulation results, the reference [6]).

\section{Cable of IFSTTAR: experimental results and ANSYS simulation}

Some results obtained in the $50 \mathrm{~m}$ length $(\ell)$ steel cable with $57 \mathrm{~mm}$ of diameter (Fig. 3) are shown. The experimental equipment in IFSTTAR, Nantes, France, (Fig. 3 right of the $50 \mathrm{~m}$ cable) permits a vertical displacement (up) of the cable by a measured force and, later, a sudden release of the stress. The action (a Heaviside return) induces oscillations on the steel cable.

The experimental observations were realized inducing oscillations in the middle of the cable without (free cable) or with the SMA damper by two NiTi wires of $1260 \mathrm{~mm}$ long. Other tests were realized situating the actuator or the damper in cable lengths as $\ell / 3, \ell / 4, \ell / 6$ and $\ell / 8$.

The vertical position of the cable (the oscillation amplitude) is detected by a laser, and the results are stored at one sampling of $300 \mathrm{~Hz}$. The Fig. 4 left shows the time evolution of the oscillation amplitude without the SMA after a return of Heaviside signal of $4000 \mathrm{~N}$. The spontaneous damping in the cable is extremely lower $(20 \%$ in one minute. The Fig. 4 right shows the effect of the two wires of NiTi SMA in the amplitude of oscillation induced by the same excitation. The effect of the SMA was highly interesting. One reduction of the oscillation amplitude to "zero" was realized in only "ten" seconds.

The data used for simulation was: the horizontal cable with a length of $50.5 \mathrm{~m}$ has a mass per unit length of $16.1 \mathrm{~kg} / \mathrm{m}$. It is made of steel $(E=200 \mathrm{GPa})$ and the initial tension is $960 \mathrm{kN}$. The cross-section of the cable is made of 159 stranded wires forming the core and 7 additional layers. The outer diameter, cross-section's area and moment of inertia are respectively $55.6 \mathrm{~mm}, 1936 \mathrm{~mm}^{2}$ and $3.03 \times 10-7 \mathrm{~mm}^{4}$. 

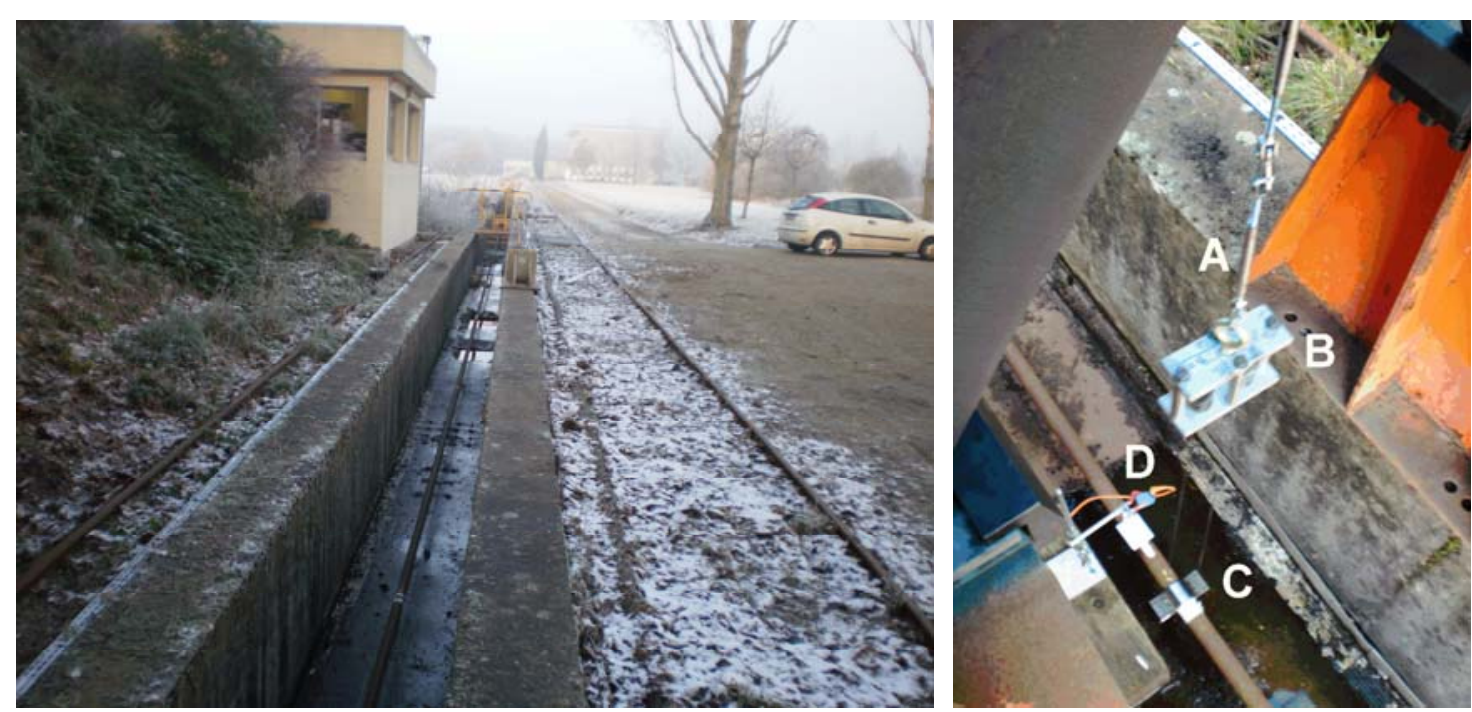

Figure 3. The cable in the IFSTTAR Nantes (France) facility (Fall 2010). Left: situated in its working position. Right: position near the center of the cable of the SMA damper with two SMA wires. A: shortened. B: fixation device up to 3 wires. C: fixation of wires in the cable. D: laser sensor.

The model is built with the finite element software ANSYS 11.0. The cable is represented by 100 beam elements (BEAM3 element type) and both extremities are clamped (displacements and rotation fixed to zero). During the first ten seconds, a $4 \mathrm{kN}$ force is gradually applied at the midpoint of the cable and instantaneously released. Afterwards, the cable freely oscillates during another 10 seconds according to the first harmonic at a frequency of $2.38 \mathrm{~Hz}$. For the calculations, the time increment used was $0.01 \mathrm{~s}$.

\section{From bilinear to cubic model}

For the action of NiTi damper two SMA of $1.26 \mathrm{~m}$ long, each of them having a diameter of $2.46 \mathrm{~mm}$ were used. The damper is modeled by a classical bilinear model implemented in ANSYS through its USERMAT capability. The main negative effect of the bilinear model relates its straight line between $\sigma(\mathrm{Af})$ and $\sigma(\mathrm{Ms})$. When the oscillation amplitude remains inside the strains of one percent (near $13 \mathrm{~mm}$ for the SMA wires of $1260 \mathrm{~mm}$ ) the simulated damper cannot realizes any action and remains some "constant" residual oscillation. When the amplitudes of the cable become sufficiently small, the damper remains in the initial linear or spring behavior without dissipation. This is in opposition to the experimental results of a series of experiments carried out with the same material where a certain amount of energy is dissipated during a cycle even for a strain reaching as strain as low as $0.4 \%$ (see Fig. 4 right). For $\mathrm{t}>20 \mathrm{~s}$, the peak-to-peak amplitude not overcomes $5 \mathrm{~mm}$, for this displacement the SMA deformation remains under $0.4 \%$.

To build the model (Fig. 5 left), four points are taken on the loading and unloading paths of an experimental curve. Two common points (start $\mathrm{M}_{0}$ and end $\mathrm{M}_{\mathrm{e}}$ points) the two other points $\left(\mathrm{L}_{1}, \mathrm{~L}_{2}\right.$ and $\mathrm{U}_{1}, \mathrm{U}_{2}$ ) for the loading and unloading path are selected from the experimental curve. The coefficients of the cubic polynomial equation $\sigma=\mathrm{c}_{3} \varepsilon+\mathrm{c}_{2} \varepsilon+\mathrm{c}_{1} \varepsilon+\mathrm{c}_{0}$ are determined by forcing the curve to pass by the four selected points in loading and in unloading. For partial loops inside the hysteresis another polynomial equation is derived by controlling the location and the slope at the beginning and at the end of the partial cycle. 

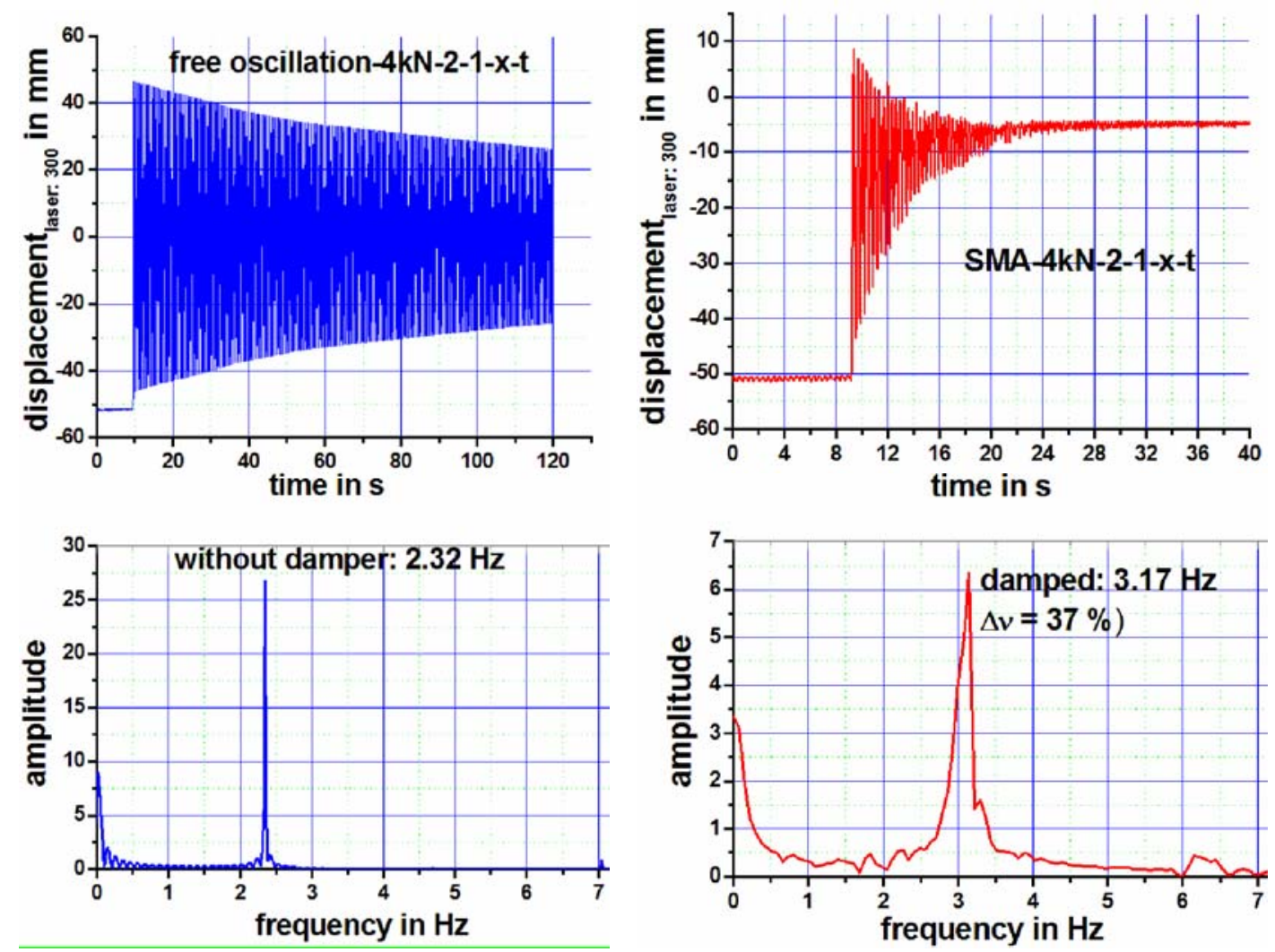

Figure 4. Experimental study of the oscillations induced in the $50 \mathrm{~m}$ length cable of IFSTTAR. Position of the actuator and damper: $\ell / 2$. Left: free oscillation behavior and associate FFT. Right: Damped behavior by SMA. The FFT was determined from the re-centered output signal.

The Fig. 5 right shows the free oscillations of the cable in comparison to the other two cases. The cubic model simulates a certain amount of dissipation by the damper even for small amplitude cycles, according to with experimental ones that the bilinear model could not achieve.
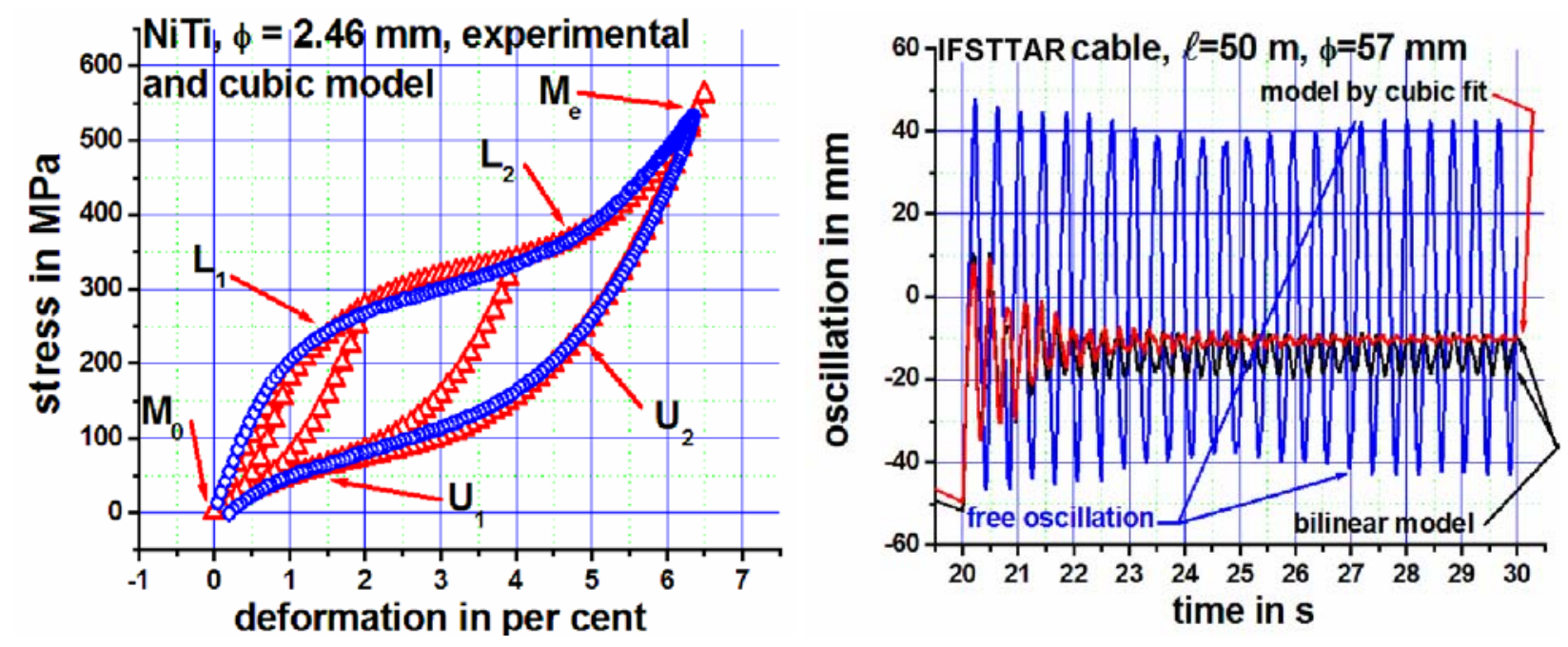

Figure 5. Left: Cubic model and experimental cycle representing the superelastic cycle in NiTi. Right: Comparison of the displacement or oscillation amplitude for the cable's midpoint in time for the tree simulations used (free, bilinear model and cubic model). 
In the bilinear model, the energy is dissipated in the very first cycles and, later, remains constant. In the cubic damper, the dissipated energy continues to increase until the oscillation amplitude of the cable is completely "vanished".

\section{Application remarks}

The global analysis permits some application ideas for the SMA dampers (NiTi wires with 2.46 $\mathrm{mm}$ of diameter). Two actions are required from the experimental analysis. The first one focuses on the length of the SMA wires. In particular, it is expected that the dampers reduce the oscillation amplitude to a half. Considering that $\mathrm{x}$ is the residual amplitude peak to peak, the required length $\ell$ of the SMA wires was $0.010 \ell \approx \mathrm{x}(\mathrm{NiTi})$.

Use of $0.010 \ell \approx \mathrm{x}$ establishes the appropriate length of SMA ensuring an extended fracture life. For instance, with this length the fracture life it's greater than 4.5 millions of working cycles with strains under $1.5 \%$. The analysis of the SMA establishes that the alloys work in clearly non-linear behavior. Some linearization is available using sets of the same wire with appropriate structure. For instance, it's satisfactory built one "hamster cage" for several wires.

The second one establishes the number of required wires $\mathrm{N}$ in comparison with the measurements realized in the ELSA (1 wire) and in the IFSTTAR ( 2 wires). In the last, the stressing force in the cable $F^{\prime}$ is $1000 \mathrm{kN}$ and cross section $S^{\prime}$ is, roughly, $\left[(\pi / 4)\{55 \mathrm{~mm}\}^{2}\right]$. For a cable stressed by a force $\mathrm{F}$ and with across section $\mathrm{S}$, the required number of SMA wires $\mathrm{N}$ was:

$\mathrm{N} \approx 2(\mathrm{~F} / \mathrm{S}) /\left(\mathrm{F}^{\prime} / \mathrm{S}^{\prime}\right)_{\text {Nantes }} \approx 2(\mathrm{~F} / \mathrm{S}) /(1000 \mathrm{kN} /[(\pi / 4)\{55 \mathrm{~mm}\} 2] \approx 2(\mathrm{~F} / \mathrm{S}) / 420 \mathrm{MPa}$

\section{Summary}

Use of SMA permits a relevant reduction of oscillations amplitude (i.e., between $1 / 2$ and $1 / 4$ ) in stayed cables with an appropriate fracture-life.

\section{Acknowledgements}

To Georges Magonette, Daniel Tirelli, and Bea Zapico (ELSA - JRC, Ispra) for their support in measurements in the cable No. 1 and to Daniel Bruhat and Richard Michel of ELSA and in the IFSTTAR cable respectively. Research work realized in the frame of the project SMARTeR (ESF 2007-09 and MICINN BIA2006-27041-E).

\section{References}

[1] K. Otsuka and X. Ren, "Physical metallurgy of Ti-Ni-based shape memory alloys": Prog. Mater. Sci, Vol. 50 (5), (2005) pp. 511-678.

[2] Information on http://en.structurae.de/structures/data/index.cfm?ID=s0000375

[3] Information on http://en.structurae.de/structures/data/index.cfm?ID=s0000046

[4] V. Torra, A. Isalgue, C. Auguet, G. Carreras, F.C. Lovey and P. Terriault, "Damping in Civil Engineering using SMA. Part II. Particular properties of NiTi for damping of stayed cables in bridges": submitted to Can. Metall. Quart. (2010)

[5] V. Torra, A. Isalgue, G. Carreras, F.C. Lovey, H. Soul, P. Terriault and B. Zapico, "The SMA properties in civil engineering applications. The SMARTeR project: Use of SMA in damping of stayed cables for bridges": ESOMAT paper 07016 (2009), DOI:10.1051/esomat/200907016, published by EDP Sciences, 2009,

[6] V. Torra, F.C. Lovey and P. Terriault, "Experimental study of damping in civil engineering structures using smart materials (CuAlBe-NiTi SMA). Applications to a steel portico and to stayed cables for bridges (the SMARTeR project)": Proceedings of the Smart Structural Systems Technologies (S(3)T $\mathrm{T}^{2010}$ ), Porto, Portugal, 6-9 April 2010, pp. 369-399. ISBN: 978-989-96697-0-3. 